Western University

Scholarship@Western

Management and Organizational Studies

Management and Organizational Studies

Publications

Department

$12-5-2019$

\title{
A Framework for Considering Dissociative Identity Effects in Consumption
}

Bonnie Simpson

Lea Dunn

Katherine White

Follow this and additional works at: https://ir.lib.uwo.ca/mospub

Part of the Business Administration, Management, and Operations Commons, and the Work, Economy and Organizations Commons 


\title{
A Framework for Considering Dissociative Identity Effects in Consumption
}

\author{
Bonnie Simpson \\ Assistant Professor in Consumer Behaviour \\ DAN Department of Management and Organizational Studies \\ Western University \\ Lea Dunn \\ Assistant Professor in Marketing \\ Foster School of Business \\ University of Washington \\ Katherine White \\ Professor in Consumer Insights, Prosocial Consumption, and Sustainability \\ Sauder School of Business \\ University of British Columbia
}

This is a draft chapter. The final version is available in Handbook of Research on Identity Theory in Marketing edited by Americus Reed and Mark Forehand, published in 2019, Edward Elgar Publishing https://www.elgaronline.com/view/edcoll/9781788117722/9781788117722.xml?rskey=PEPpKX $\underline{\text { \&result }=1}$

The material cannot be used for any other purpose without further permission of the publisher and is for private use only. 


\title{
Quick Chapter Overview
}

In this chapter, we focus on the observation that although people are often influenced by groups that carry positive associations (i.e., membership groups they belong to and aspirational groups they admire), the motivation to avoid particular groups can also lead to compelling influences on consumer attitudes and behaviors. We refer to this avoidance effect (striving to not be seen as or associated with a negatively viewed "other") as dissociation. In this chapter, we delineate three processes that drive dissociation effects: 1) consistency threat-consumers choose not to purchase a particular product because the group that has adopted it does not resonate with their private sense of self (and choosing this option would threaten self-consistency); 2) negative information - consumers will avoid products they view as imbuing their own identity with negative associations; and 3) misidentification avoidance - consumers will abandon products or preferences to avoid being misidentified by others as a member of a dissociative group. Further, we identify a fourth process, positive identity contrast, whereby a dissociative referent can lead to approach behaviors to positively differentiate the self from the dissociative group. We provide evidence for these dissociative processes and discuss future directions for research that explore solutions to overcoming dissociative effects. Practitioners can draw on this chapter to determine appropriate means to communicate or advertise a product relative to their target market, and also when non-target groups adopt their product. Consumers, through an understanding of dissociative motives, may be able to better accept and respond to dissociative out-groups. Finally, we explore dissociation through the perspective of how polarizing the world has become in many facets of life, such that demonstrating who you are not carries more weight than who you are. By understanding how and why dissociation occurs, consumers may be able to overcome these motives in ways that lead to a more cohesive and compassionate understanding of others.

\begin{abstract}
In this chapter we examine the mirror image of the identity association principle (Reed et al. 2012) - dissociation. While the association principle posits that stimuli associated with a positively regarded identity receive more positive evaluations, the dissociation principle suggests that stimuli associated with negatively regarded identities will receive negative evaluations and be abandoned. We focus on the nature of dissociative reference groups or groups the consumer is motivated to avoid association with, and we present a framework outlining how dissociative influence can impact consumer behavior. We review the literature on dissociative influence and note that although dissociative reference groups often spur avoidance behaviors, they can sometimes induce approach behaviors. We then turn to a discussion of how dissociative associations can lead to polarizing reactions in real-world domains, such as politics. Finally, we draw on our theorizing to outline some suggested directions for future research in this regard.
\end{abstract}


One way in which individuals form, contextualize, and maintain a sense of their own identity is by associating the self with a given category label (e.g., familial roles, gender, nationality, etc.; Reed et al. 2012). Such category-based identity formation is often driven by associations with relevant social group memberships (or reference groups; White and Dahl 2006; Tajfel and Turner 1979). Much of the extant research on social group influence centers on positive reference groups-groups that individuals associate with in some way, such as membership groups (i.e., groups that an individual belongs to and feels a part of) and aspirational groups (i.e., groups to which an individual aspires to be a part of; Bearden and Etzel 1982; Escalas and Bettman 2003, 2005). A large body of literature has demonstrated that individuals prefer to act in ways that allow them to reinforce their connections with positive social groups (Bearden and Etzel 1982; Childers and Rao 1992; Cialdini and Goldstein 2003). Indeed, the identity association principle proposed by Reed and his collagues (Reed et al. 2012) proposes that when stimuli become associated with a positively regarded identity (e.g., a positive reference group), those stimuli will themselves garner more positive evaluations. We focus on the influence of the mirror of this associative principle — dissociation, or the notion that individuals are often motivated to avoid undesired identities (White and Dahl 2006; 2007). In this chapter, we review the research demonstrating that people often are driven by the desire to avoid associating with undesired identities. Moreover, we introduce a conceptual framework of dissociative influence that examines the distinct processes by which dissociative effects can occur and use this to propose novel directions for future research. 


\section{The Nature of Reference Groups and How They Shape Identity}

One view of consumption is that people choose products, brands, and behaviors that allow them to construct and maintain their identities, as well as to communicate their identities to others (Belk 1988; Kleine et a.1993). In addition to a sense of personal identity (i.e., related to one's individual sense of self), people hold social identities (i.e., related to the groups to which one belongs or is affiliated; Tajfel and Turner 1979). Thus, people are likely to consume products and brands that represent, reinforce, and maintain positive aspects of either their own personal identity or an identity linked to a social group membership (Escalas and Bettman 2003). The majority of work examining the influence of social group memberships on consumption finds that consumers are motivated be seen in a positive light and, thus, are more likely to prefer and purchase products or brands used by in-group and/or aspirational group members (Bearden and Etzel 1982; Childers and Rao 1992; Escalas and Bettman 2003).

By consuming in ways that are congruent with positively viewed social groups, individuals are able to positively construct, maintain, and communicate identities (Belk 1988; Richins 1994). We might, for instance, purchase a certain type of product (e.g., a pair of Nike running shoes) because it is associated with a group we aspire to (e.g., successful athletes), and through doing so we can signal to ourselves and others with whom and what we identify. According to McCracken (1989), products hold meaning as a function of the characteristics of who uses them. When social group members use and display products, associations related to group characteristics can be transferred to the product or brand. Indeed, work suggests that brands linked to positively viewed social identities become connected to consumers' mental representations of the self in ways that allow the consumer to create, cultivate, and define their self-concepts (Escalas and Bettman 2003, 2005; Escalas et al. 2019). 
The fact that the majority of the relevant literature demonstrates that positively viewed social identities (e.g., membership and aspirational groups) are most likely to be utilized in the creation, definition, and communication of identity highlights the primacy of what researchers have called the identity association principle — people will respond more positively to stimuli that have somehow become associated with a positively regarded identity (Reed et al. 2012). Importantly, however, the literature has begun to take an interest in social groups that represent identities or groups with which one does not wish to associate. While "out-groups" refer to reference groups to which an individual does not belong, "dissociative groups" are those that an individual wants to actively avoid associated with (Englis and Solomon 1995; White and Dahl 2006, 2007). We propose that, akin to the identity association principle, a dissociation principle also exists wherein consumers are motivated to avoid association with stimuli that have become linked to a negatively viewed dissociative group (White and Dahl 2006, 2007).

\section{A Framework for Dissociative-Reference-Group Effects}

Consistent with how they respond to positive reference groups, consumers similarly rely on dissociative groups as a social category to form, contextualize, and maintain their sense of self-identity. For instance, when a product or action becomes associated with a negatively regarded identity (dissociative group), it often will receive negative evaluations and be avoided by the consumer (White and Dahl 2006, 2007). We put forth a conceptualization recognizing that dissociation is a mirror image of the identity association principle (Reed et al. 2012), whereby stimuli that become associated with a negatively regarded dissociative group will receive negative evaluations (Dunn et al. 2013). We then posit that dissociative avoidance effects can emerge as a function of one of three processes: consistency threat, negative information 
avoidance, and misidentification avoidance. Finally, while dissociative effects most often result in avoidance responses, emerging literature suggests that this may not always be the case. As such, the potential for approach effects is discussed via the fourth dissociative process in the framework, positive identity contrast, by which consumers can become inclined to engage in consumption behaviors consistent with those of a dissociative reference group.

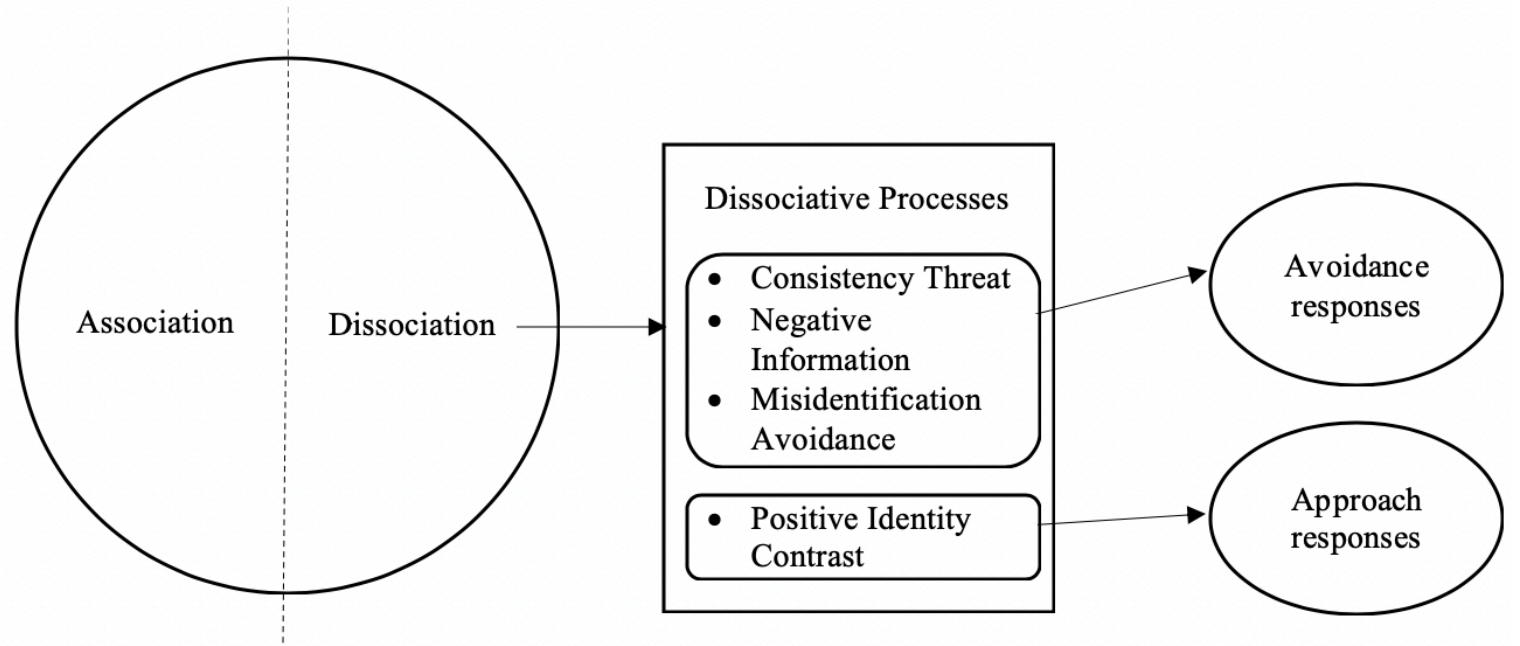

Figure 1. A framework for dissociative-reference-group effects

Consistency Threat. The first process by which dissociative influence operates is one wherein dissociative association is perceived as a threat to the consistency of the individual's private self-concept. If the consumer uses a product or engages in a behavior that is strongly linked to a dissociative social group, this can be an inconsistency threat to how the consumer views the self. Thus, to protect one's self-identity, consumers may avoid behaviors, products, or brands that are somehow linked to dissociative groups. In one example, White and Dahl (2007) demonstrated that consumers will avoid associating with dissociative groups, but not out-groups 
more generally. For instance, Canadians avoided choosing a pen that was associated with American identity, an out-group that they are motivated to establish their distinctiveness from. However, Canadians did not display avoidance of a neutral out-group, such as being Belgian. Consistent with the notion that these effects are driven by threats to the individual selfconsistency, the effects were heightened under conditions where the individual self-concept was primed in some way or when the in-group identity (i.e., being Canadian) was particularly important to participants.

In other work, males have been shown to avoid options that are linked to being female. While males do not necessarily think negatively of females, they are motivated to maintain a sense of identity that is not associated with being "feminine." For example, males will avoid a steak when it is called the "ladies" cut" versus when it is simply called the "chef"s cut" (White and Dahl 2006). Other work shows that males will avoid engaging in "green" behaviors such as recycling or using reusable bags because being eco-friendly is associated with "femininity," representing a dissociative social category of female that is inconsistent with their masculine identity (Brough et al. 2016). Supporting the notion that this is driven by a consistency threat, the effects were enhanced when masculinity was threatened in some way and mitigated when masculinity was affirmed. Similarly, males may avoid ethically responsible brands because such brands are associated with being "warm," which is viewed an inherently feminine trait (Antonetti and Maklan 2016; see also Shang and Peloza 2016).

In another line of inquiry, Naylor et al. (2012) found that simply having information about the dissimilarity of a group's composition on a brand's social media page is enough to lower evaluations of the brand. Specifically, when the brand's fans were made up of homogenously dissimilar individuals, consumers had less positive attitudes toward the brand 
than when the composition represented an in-group of similar others or even a balance of similar and dissimilar others. The research found that this effect occurred because the consumer inferred that they had less in common with the 'typical shopper' when dissimilar others were represented in the social media feed. Taken together, the literature demonstrates that dissociative groups often lead to avoidance effects because they represent a choice that is incongruent with how the consumer privately views his or her own self-concept.

Avoidance of Negative Identity Information. In addition to dissociative responses that occur as a result of self-consistency threats, research has also considered how individuals avoid linking negative associations with their own self-concept. For instance, in order to maintain an overall positive self-perception, consumers may distance themselves from integral identities when these identities become negatively imbued in some way (i.e., threatened; Spangenberg and Angle 2019) and engage in compensatory consumption (Rucker and Cannon 2019). Thus, when consumers receive information that casts social categories they belong to in a negative light, they will often avoid those negative elements of their identity via avoidance of associated products (White and Argo 2009; White et al. 2018). For example, White and Argo (2009) examined how social identity threat influences consumer preferences for identity-relevant versus irrelevant products. They found that when a consumer's own gender identity was threatened, participants low in collective self-esteem (Luhtanen and Crocker 1992) were subsequently more likely to avoid products associated with their own gender. By avoiding these products, one is able to reaffirm a sense of positive self-worth.

Building on this work, White et al. (2012) found that self-construal relates to how consumers respond to social identity threat. Specifically, consumers with a more independent self-construal were more likely to avoid products associated with the threatened identity. This 
occurs because those with an independent self-construal are more likely to see the social identity threat as a threat to their self-worth, and thus avoid products in an effort to reaffirm their selfworth. On the other hand, those with a more interdependent self-construal are more likely to see the social identity threat as a threat to their sense of belonging and cope with the threat by associating their the ingroup identity, even when it is threatened. Finally, White et al. (2018) found that, in private, when consumers are likely considering the private self-concept, they avoided products associated with their own in-group (e.g., university, city, or occupation) when it was cast in a negative light. Thus, one key process that leads to dissociative responses is one wherein the consumer protects the individual self from association negative identity associations.

Avoiding Misidentification. The third dissociative process is grounded in a desire to avoid misidentification. This desire arises when there is a concern that others might mis-categorize the individual as belonging to a dissociative out-group. An important distinction from consistency threat, then, is that rather than a private threat to the self, a public or identity-signaling element must be present for the misidentification process to be activated. For example, White and Dahl (2006) found that men were more likely to avoid and negatively evaluate a steak selection when it was described in terms of a dissociative out-group (e.g., ladies' cut steak) than when associated with a neutral group (e.g., chef's cut steak). While this occurred in private (due to consistency threat), the effects were amplified when the behavior was to be public, and it was heightened for those who were particularly concerned with the image of the self they convey to others. Thus, the observed effects were due at least in part to a desire to avoid other people misidentifying the consumer as displaying behaviors linked to a dissociative group.

Importantly, unlike the consistency threat mechanism, this process is related to the verification principle (i.e., how consumers use external and social information to determine their 
progress toward their ideal representation of an identity; Reed et al. 2012), as consumers will abandon previously held tastes when these choices become threatened by dissociative group use (Spangenberg and Angle 2019). Berger and Heath $(2007,2008)$ examined when people might be more or less likely to diverge from the preferences of others, finding that when a dissociative group adopts the use of a preferred product category that clearly signals identity (e.g., music, but not dish soap), consumers are likely to abandon (or perhaps hide; Thomas et al. 2015) their preferences to avoid being misidentified as a group member. Interestingly, work by Bellezza and Keinan (2014) found a way to avoid abandonment when a brand becomes adopted by a dissociative group. Specifically, they found that when the dissociative group did not claim a brand as its own but instead discussed their use as a "brand tourist," individuals were less likely to abandon the brand.

In addition, other work has found explicit ways to use dissociative groups to positively change an individual's behavior. For example, Berger and Rand (2008) found that an effective way to get consumers (i.e., undergraduates) to avoid engaging in negative behaviors such as eating junk food and underage drinking is to communicate that the behavior is primarily conducted by a dissociative group (i.e., graduate students). They found that the primary reason for avoiding the behaviour was to avoid being treated as a member of the dissociative group, and thus those who were high in self-monitoring (who control their actions to achieve a desired public image) were more likely to avoid dissociative behaviours. Though while some past work suggests that exposure to stereotyped dissociative consumers (such as obese individuals) might activate stereotype-consistent goal commitment (e.g., low commitment to health), and thus result in stereotype-consistent behavior (e.g., indulgent consumption; Campbell and Mohr 2011), McFerran et al. (2010) found that when other individuals were present (i.e., the behavior was 
public) consumers anchored their food consumption quantity on the choices of a dissociative other. For example, when an obese consumer chose a large amount of unhealthy or healthy food, the participants were more likely to choose a small amount of unhealthy or healthy food.

Similarly, if the obese consumer chose a small amount of unhealthy or healthy food, participants were more likely to take a large amount. In this case, the motivation to avoid a behavior similar to that of the dissociative group resulted in an adjusted food quantity, regardless of whether or not this was goal-consistent (e.g., health-consistent).

Positive Identity Contrast. The first three processes outlined in the framework share a commonality in that they focus on ways in which dissociative social categories lead consumers to diverge from or avoid certain products, brands, or behaviors. The fourth process we highlight, positive identity contrast, thus raises a critical distinction in the literature-dissociative groups may not always lead to avoidance responses. Some research shows, for example, that one might actually exhibit an approach response to products or behaviors associated with a dissociative group. Counterintuitively, we note that such results could be viewed as being a form of identity contrast, wherein individuals engage in the focal behavior displayed by the dissociative group to create a comparative affirmation that they are positively distinct from the dissociative group.

For instance, work on ironic consumption has found that consumers may actively approach a dissociative-group product or brand if they are doing so in an ironic fashion (Warren and Mohr 2018). By engaging in a behavior that is congruent with a dissociative identity in an ironic fashion, the consumer is showing how his or her own identity positively (in their own view) contrasts with the identity of the core users. In another example, Shalev and Morwitz (2012) found that when a counter-stereotypical product user (e.g., someone who is viewed as low-status) positively evaluates a product, this can lead to more positive product evaluations on 
the part of an observer. On the face of it, one might expect that the low-status user would be viewed as dissociative and that a negative evaluation might emerge. However, the authors propose that this effect occurs because comparing oneself to a low-status (i.e., dissociative) user (who is typically not expected to use the product) can lead to a decreased evaluation of the self (e.g., 'wow, even this dissociative individual has access to this product that I don't'). As a result, the individual may purchase the same product in an attempt to positively contrast the self relative to the counter-stereotypical user, and thus restore positive distinctive feelings about the self.

Research also indicates that when a dissociative group publicly performs well on a positively viewed action (e.g., environmental conservation activities), this acts as a threat to consumers' group identity and motivates them to perform well to affirm the positivity of the ingroup (White et al. 2014). In other words, individuals make a comparison (i.e., contrast) between their own group and the dissociative group and, as a result, seek to perform even better in terms of the positively viewed behavior. Finally, Dommer et al. (2013) found that when low-selfesteem individuals feel socially excluded (i.e., feel different from, contrasted against the in-group others), they are more likely to horizontally differentiate themselves by seeking affiliation with another group through consumption of out-group products as a means of reaffirming self-esteem. Thus, rather than always avoiding the behaviors of a dissociative group (Berger and Rand 2008; White and Dahl 2006, 2007), our framework illustrates that through the positive identity-contrast process consumers can be motivated to emulate behavior engaged in by a dissociative group.

\section{Directions for Future Research}

Our theoretical framework suggests that consumers not only form, cultivate, and communicate their self-concepts by associating with positively viewed identities (Reed et al. 
2012; Tajfel and Turner 1979), they also do so by avoiding identities that they wish to differentiate the self from (Markus and Nurius 1986; White and Dahl 2006). We highlight the key processes underlying dissociative identity effects and how they can be used to organize the existing literature; and we next suggest that they point to promising directions for future research.

First, while past research demonstrates that consumers are motivated to avoid dissociative options due to a desire to avoid identity inconsistency, future research could examine how to mitigate such negative reactions. One interesting and important practical context where avoiding identity inconsistency plays out is the emerging polarized political landscape where individuals are indiscriminately clinging to partisan memberships, not because of beliefs about the issues but because of a desire to avoid association with the other political party (Cohn 2014). Such divisiveness is on the rise and can lead to disparagement or negative stereotyping of out-groups (Theodoridis 2016). For example, in the United States there has been a substantial shift toward negative partisanship or negative affect toward the opposing political party (Abramowitz and Webster 2016).

One question for future research, then, is how might we overcome such dissociative divides? One possible solution may lie in the fluidity and flexibility of the self-concept, which is composed of numerous and varied identities (Markus and Kunda 1986). Different identities can become relatively more activated and influence our cognitions and behaviors, depending on the situation (Tajfel and Turner 1979), and situational cues can make certain identities more salient than others (Forehand et al. 2002; Reed 2004; Reed and Forehand 2016). Thus, one solution to overcoming dissociation could be to activate a superordinate identity that subsumes that which the consumer is motivated to dissociate from. For example, could activating a superordinate 
identity (e.g., American) assuage the dissociative effects of a political identity (e.g., Democrat) when faced with the actions of a dissociative group (e.g., Republican)? Past work has found promising effects of identity recategorization in overcoming dissociative reactions to out-groups (Gaertner et al. 1993; Levine et al. 2005). We proposed that such an approach might similarly reduce negative reactions to dissociative groups based on political affiliations.

Preliminary work in our lab explored whether activating an 'American' identity versus a 'Republican' identity on a volunteer's t-shirt could impact the extent to which Democrats were willing to give money to a fictional employment training charity associated with the Republican party. In addition, we examined whether differences would be more pronounced for those who felt highest in affective polarization (i.e., the degree to which a person feels emotional extremes when thinking about the dissociative party [Iyengar et al. 2012; Iyengar and Westwood 2015]). American participants $(n=200)$ who self-identified as Democrats were asked to read some information about an organization that was described as having an affiliation with Republicans. Participants were then asked to imagine encountering a volunteer for this organization outside the grocery store. We manipulated the wording on the volunteer's t-shirt such that it highlighted a Republican group membership or a superordinate (American) identity membership. We also had participants complete a measure of affective polarization (Garrett et al. 2014). While making a particular identity salient via the volunteer's t-shirt had no impact on those low in affective polarization (they were equally willing to give to the charity regardless), those highest in affective polarization exhibited greater intentions to give when the volunteer signaled an "American" identity versus a "Republican" identity. These data provide initial evidence that when affective polarization is high, communicating a superordinate identity (i.e., American) might decrease polarized reactions to a dissociative group (i.e., Republican). 
While re-categorization is one potential idea on how to decrease negative outcomes of dissociation due to self-consistency threat, there are likely to be other possible solutions. As suggested by Choi and Winterich (2013), individual differences such as moral identity may decrease perceived social distance and increase willingness to try a dissociative brand. One potential direction for research to examine the mitigation of dissociative influence then is to enhance a sense of moral identity and expand the circle of moral regard to include dissociative group members (Reed and Aquino 2003). Moreover, activities and communications that enhance perspective taking, which can increase empathy, may similarly help decrease this perceived social distance (Batson et al. 1997; Dovidio et al. 1990). In sum, we propose that future research might profitably resolve consistency threats by examining moderators of dissociative avoidance effects in ways that cultivate greater inclusion of or understanding of the dissociative group.

Second, work could examine ways to resolve dissociative influence stemming from wanting to avoid negative information that is associated with the consumer's own self-concept. While White and Argo (2009) discuss how consumers may distance themselves from identityrelated products when the focal social identity is threatened, it could be interesting to see if the same effect would occur when the identity itself is not threatened, but one's place as a representative of that identity is threatened (e.g., you are not a good representative of that category). For example, working mothers might be called out for not being a good enough mother because they need to devote time to work as well as family. Conversely, stay-at-home mothers may also be berated for not being a progressive enough woman. How does communication like this change how consumers hold or express their held identity? Would consumers be likely to avoid in-group products (e.g., Dommer et al. 2013; White and Argo 2009)? Or might they reaffirm their commitment to the group and "double-down" on the 
identity, choosing more identity-related products or even more conspicuous identity-related products (e.g., White et al. 2018)?

Third, research could further explore when consumers dissociate from products to avoid being misidentified by other consumers. For example, future research could examine the intricacies of the conditions under which dissociative group adoption would lead to abandonment. The work of Bellezza and Keinan (2014) suggests that adoption by a dissociative other will not lead to abandonment of a brand if the dissociative user does not claim to be part of the core brand group. Similarly, work by Han et al. (2010) finds that elite users of the brand may be less likely to abandon the brand when "poseurs" begin using it, but instead buy less conspicuous versions that are less likely to be recognized except by other elites. Could it be, then, that abandonment of a taste or product might depend on how conspicuous the consumption of the product is by the dissociative group? For example, would it be more of a threat if the dissociative group were to adopt a product that was more conspicuous (high brand prominence, "louder") or if members of the group were more vocal about their use of the product compared to if the product was inconspicuous or the dissociative group less vocal about product use?

Fourth, in regard to the identity-contrast process, future research could explore whether there are elements of the product, brand, or cause that the dissociative group is advocating that may lead to acceptance by the consumer. In the realm of prosocial behavior, would it be possible to obtain increased donations for a cause advocated for by the dissociative group if the charity highlighted a universal need? Or, could social clout play into the adoption of products used by the dissociative group? For example, if the product or brand boasted extreme acceptance, luxury, status, or an element that was being elevated by society at large, would this lead to greater adoption by the consumer? 


\section{Conclusion}

In this chapter we have presented a theoretical framework that highlights the processes by which dissociative identity effects can operate. We review the research literature on dissociative identity effects via this lens and then we turn to highlighting potential directions for future research. We hope that our conceptualization will help to spur further theoretical advances, as well as additional research in the domain of dissociative influence. 
References

Abramowitz, A.I. and S. Webster (2016), 'The rise of negative partisanship and the nationalization of U.S. elections in the $21^{\text {st }}$ century,' Electoral Studies, 41 (March), 12 22.

Antonetti, P. and S. Maklan (2016), 'Hippies, greenies, and tree huggers: how the 'warmth' stereotype hinders the adoption of responsible brands,' Psychology \& Marketing, 33 (10), $796-813$.

Batson, C.D., K. Sager, E. Garst, M. Kang, K. Rubchinsku, and K. Dawson (1997), 'Is empathyinduced helping due to self-other merging,' Journal of Personality and Social Psychology, 73 (3), 495-509.

Bearden, W.O. and M.J. Etzel (1982), 'Reference group influence on product and brand purchase decisions,' Journal of Consumer Research, 9 (2), 183-194.

Belk, R.W. (1988), 'Possessions and the extended self,' Journal of Consumer Research, 15, 139_ 167.

Bellezza, S. and A. Keinan (2014), 'Brand tourists: How non-core users enhance the brand image by eliciting pride,' Journal of Consumer Research, 41 (2), 397-417.

Berger, J. and C. Heath (2007), 'Where consumers diverge from others: identity signaling and product domains,' Journal of Consumer Research, 34, 121-134. 
_- (2008), 'Who drives divergence? Identity signaling, outgroup dissimilarity, and the abandonment of cultural tastes,' Journal of Personality and Social Psychology, 95 (3), 593-607.

Berger, J. and L. Rand (2008), 'Shifting signals to help health: using identity signaling to reduce risky health behaviors,' Journal of Consumer Research, 35, 509-518.

Brough, A.R. J.E.B. Wilkie, J. Ma, M.S. Isaac, and D. Gal (2016), 'Is eco-friendly unmanly? The green-feminine stereotype and its effect on sustainable consumption,' Journal of Consumer Research, 43 (4), 567-582.

Campbell, M. and G.S. Mohr (2011), 'Seeing is eating: How and when activation of a negative stereotype increases stereotype-conducive behavior,' Journal of Consumer Research, 38 (3), 431-444.

Chan, C., J. Berger, and L. Van Boven (2012), 'Identifiable but not identical: Combining social identity and uniqueness motives in choice,' Journal of Consumer Research, 39 (3), 561573.

Childers, T.L. and A. Rao (1992), 'The influence of familial and peer-based reference groups on consumer decisions,' Journal of Consumer Research, 19 (2), 198-211.

Choi, W.J. and K.P Winterich (2013), 'Can brands move in from the outside? how moral identity enhances out-group brand attitudes,' Journal of Marketing, 77 (2), 96-111.

Cialdini, R.B. and N.J. Goldstein (2003), 'Social influence: Compliance and conformity,' Annual Review of Psychology, 55, 591-621. 
Cohn, N. (2014), 'Polarization is dividing American society, not just politics,' The New York Times, retrieved from: https://www.nytimes.com/2014/06/12/upshot/polarization-isdividing-american-society-not-just-politics.html

Dommer, S.L., V. Swaminathan, and R. Ahluwalia (2013), 'Using differentiated brands to deflect exclusion and protect inclusion: The moderating role of self-esteem on attachment to differentiated brands,' Journal of Consumer Research, 40 (4), 657-675.

Dovidio, J.F., J.L. Allen, and D.A. Schroeder (1990), 'Specificity of empathy-induced helping: Evidence for altruistic motivation,' Journal of Personality and Social Psychology, 59 (2), 249-260.

Dunn, L., K. White, and D. Dahl (2013), 'That is so not me: Dissociating from undesired consumer identities,' in Ayalla A. Ruvio and Russell W. Belk (eds), The Routledge Companion to Identity and Consumption, New York: Routledge.

Englis, B.G. and M.R. Solomon (1995), 'To be or not to be? Lifestyle imagery, reference groups, and the clustering of America,' Journal of Advertising, 24, 13-28.

Escalas, J.E., I. Gallo, and T. Gaustad (2019), ‘Reminiscing on self-brand connections: Differentiating experiential versus symbolic origins,' in Mark Forehand and Americus Reed (eds), Handbook of Research on Identity Theory in Marketing, Northampton, MA: Edward Elgar Publishing Inc. 
Escalas, J.E. and J.R. Bettman (2003), 'You are what you eat: The influence of reference groups on consumers' connections to brands,' Journal of Consumer Psychology, 13 (3), 339348.

(2005), 'Self-construal, reference groups, and brand meaning,' Journal of Consumer Research, 32 (3), 378-389.

Forehand, M.R., R. Deshpandé, and A. Reed II (2002), 'Identity salience and the influence of differential activation of the social self-schema on advertising response,' Journal of Applied Psychology, 87 (6), 1086-1099.

Gaertner, S.L., J.F Dovidio, P.A. Anastasio, B.A. Bachman, and M.C. Rust (1993), 'The common ingroup identity model: Recategorization and the reduction of intergroup bias,' European Review of Social Psychology, 4 (1), 1-26.

Garrett, R.K., S.D Gvirsman, B.K Johnson, Y. Tsfati, R. Neo, and A. Dal (2014), 'Implications of pro- and counterattitudinal information exposure for affective polarization,' Human Communication Research, 40 (3), 309-332.

Han, Y.J., J.C. Nunes, and X. Dreze (2010), 'Signaling status with luxury goods: The role of brand prominence,' Journal of Marketing, 74 (4), 15-30.

Iyengar, S., G. Sood, and Y. Lelkes (2012), 'Affect, not ideology: A social identity perspective on polarization,' Public Opinion Quarterly, 76 (3), 405-431.

Iyengar, S. and S.J. Westwood (2015), 'Fear and loathing across party lines: New evidence on group polarization,' American Journal of Political Science, 59 (3), 690-707. 
Kleine, R.E., S.S. Kleine, and J.B. Kernan (1993), 'mundane consumption and the self: A socialidentity perspective,' Journal of Consumer Psychology, 2 (3), 209-235.

Levine, M., A. Prosser, D. Evans, and S. Reicher (2005), 'Identity and emergency intervention: How social group membership and inclusiveness of group boundaries shape helping behavior,' Personality and Social Psychology Bulletin, 31 (4), 443-453.

Luhtanen, R. and J. Crocker (1992), ‘A collective self-esteem scale: Self-evaluation of one’s social identity,' Personality and Social Psychology Bulletin, 18 (3), 302-318.

Markus, H. and Z. Kunda (1986), 'Stability and malleability of the self-concept,' Journal of Personality and Social Psychology, 51 (4), 858-866.

Markus, H. and P. Nurius (1986), 'Possible selves,' American Psychologist, 41 (9), 954-969.

McCracken, G. (1989), 'Who is the celebrity endorser? Cultural foundations of the endorsement process,' Journal of Consumer Research, 16 (1), 310-321.

McFerran, B., D.W. Dahl, G.J. Fitzsimons, and A.C. Morales (2010), 'I'll have what she's having: Effects of social influence and body type on the food choices of others,' Journal of Consumer Research, 36 (6), 915-929.

Naylor, R.W., C.P Lamberton, and P.M. West (2012), 'Beyond the 'like' button: The impact of mere virtual presence on brand evaluations and purchase intentions in social media settings,' Journal of Marketing, 76 (6), 105-120. 
Reed, A. (2004), 'Activating the self-importance of consumer selves: Exploring identity salience effects on judgments,' Journal of Consumer Research, 3 (2), 286-295.

Reed, A. and K. Aquino (2003), 'Moral identity and the expanding circle of moral regard toward out-groups,' Journal of Personality and Social Psychology, 84 (6), 1270-1286.

Reed, A. and M.R. Forehand (2016), 'The ebb and flow of consumer identities: The role of memory, emotions and threats,' Current Opinion in Psychology, 10 (October), 94-100.

Reed, A., M.R. Forehand, S. Puntoni, and L. Warlop (2012), 'Identity-based consumer behavior,' International Journal of Research in Marketing, 29, 310-321.

Richins, M.L. (1994), 'Valuing things: The public and private meanings of possessions,' Journal of Consumer Research, 21 (3), 504-521.

Rucker, D.D. and C. Cannon (2019), 'Identity and compensatory consumption,' in Mark Forehand and Americus Reed (eds), Handbook of Research on Identity Theory in Marketing, Northampton, MA: Edward Elgar Publishing Inc.

Shalev, E. and V.G. Morwitz (2012), 'Influence via comparison-driven self-evaluation and restoration: the case of the low-status influencer,' Journal of Consumer Research, 38 (5), 964-980.

Shang, J. and J. Peloza (2016), 'Can 'real' men consume ethically? How ethical consumption leads to unintended observer inference,' Journal of Business Ethics, 139 (1), 129-145. 
Spangenberg, K. and J. Angle (2019), 'Associations matter: Revisiting the threat typology model,' in Mark Forehand and Americus Reed (eds) Handbook of Research on Identity Theory in Marketing, Northampton, MA: Edward Elgar Publishing Inc.

Tajfel, H. and J.C. Turner (1979), An integrative theory of intergroup conflict, Monterey, CA: Brooks/Bole.

Theodoridis, A.G. (2016), 'The hyper-polarization of America,' Scientific America, retrieved from https://blogs.scientificamerican.com/guest-blog/the-hyper-polarization-of-america/

Thomas, V.L., R.D. Jewell and J.W. Johnson (2015), 'Hidden consumption behaviour: An alternative respond to social group influence,' European Journal of Marketing, 49 (3/4), $512-31$.

Warren, C. and G. S. Mohr (2018), 'Ironic Consumption,' Journal of Consumer Research, ucy065, https://doi.org/10.1093/jcr/ucy065.

White, K. and J.J. Argo (2009), 'Social identity threat and consumer preferences,' Journal of Consumer Psychology, 19, 313-325.

White, K. and D.W. Dahl (2006), 'To be or not be? The influence of dissociative reference groups on consumer preferences,' Journal of Consumer Psychology, 16 (4), 404-414. (2007), 'Are all out-groups created equal? Consumer identity and dissociative influence,' Journal of Consumer Research, 34 (4), 525-536. 
White, K., J.J. Argo, and J. Sengupta (2012), 'Dissociative versus associative responses to social identity threat: the role of consumer self-construal,' Journal of Consumer Research, 39 (4), 704-719.

White, K., B. Simpson, and J.J. Argo (2014), 'The motivating role of dissociative out-groups in encouraging positive consumer behaviors,' Journal of Marketing Research, 51 (4), 433447.

White, K., M. Stackhouse, and J.J. Argo (2018), 'Identity reinforcing consumption: The role of social identity threat and public self-awareness,' Organizational Behaviour and Human Decision Processes, 144, 60-73. 